\title{
Facility Monitoring and Construction of Geospatial Information Using Latest Exploration Technology
}

\author{
Joon Kyu Park ${ }^{1}$ and Keun Wang Lee ${ }^{2 *}$ \\ ${ }^{1}$ Department of Civil Engineering, Seoil University, 28, Yongmasan-ro 90-gil, Jungnang-gu, Seoul, Korea \\ ${ }^{2}$ Department of Multimedia Science, Chungwoon University, 113, Sukgol-ro, Nam-gu, Incheon, Korea
}

(Received October 15, 2021; accepted January 18, 2022)

Keywords: ground-penetrating radar, pavement density profiler, road pavement density, underground facility

A method that can measure the road density in the field is very effective in managing and maintaining road quality. However, the conventional density measurement method has a disadvantage that it is difficult to use in the field because it requires much time. In this study, road density measurement and underground facility exploration were performed using groundpenetrating radar (GPR). A value of 2.1-3.1 g/ $\mathrm{m}^{3}$ was obtained through a road density test of the study site by measuring the road density. A pavement density profiler (PDP) is very efficient because values in the field can be checked more simply than by the conventional method of calculation through an indoor experiment. In addition, for exploring underground facilities, the water pipes of the study site were measured and their measured values were compared with the actual measured values. The accuracy of the underground facility exploration using GPR was $0.06-0.19 \mathrm{~m}$. This means that the criteria for surveying underground facilities are satisfied. The use of GPR for underground facility surveying can enable the exact location and depth of piping to be recorded, which can greatly increase the efficiency of the work involved.

\section{Introduction}

Ground-penetrating radar (GPR) is a survey tool that detects a specific object in a stratum through radar survey to detect and locate a target by radiating high-frequency electromagnetic wave signals. ${ }^{(1,2)}$ The GPR survey uses high-frequency radar waves, allowing high-resolution images of a heterogeneous underground zone to be obtained continuously. ${ }^{(3,4)}$ Therefore, it is possible to obtain information on the inside of structures and the ground quickly and economically, so its application targets in various fields include the detection of underground buried objects, cavities, and abnormalities in tunnels. ${ }^{(5-7)}$ Compared with other survey methods, the GPR survey rapidly obtains very accurate results, so such results are used for the safety diagnosis of structures. In Korea, the GPR survey has been mainly applied to the rear cavities of tunnels or to determine the presence and location of buried objects. ${ }^{(8,9)}$ The GPR survey measures the depth of an abnormal object through the arrival speed of the wave reflected from the object by transmitting a radar wave through the stratum.

${ }^{*}$ Corresponding author: e-mail: kwlee@,chungwoon.ac.kr

https://doi.org/10.18494/SAM3708 
GPR uses electromagnetic waves to acquire information about the condition of complex underground structures, such as buried structures that cannot be examined with the naked eye, as well as phenomena of social interest such as ground depression due to the aging of underground pipes. It has recently been widely applied in various fields, and there have been many studies related to GPR. ${ }^{(10)}$ A study was conducted to find evidence of settlement due to the deterioration of a gravel layer by applying GPR on a gravel track. ${ }^{(11)}$ The applicability of GPR was examined through an indoor experiment. In addition, it was found that the boundary between the furrow layer and the gravel layer formed indoors can be relatively accurately distinguished by the GPR survey. In the study, ${ }^{(1)}$ the applicability of GPR was evaluated by proving the boundary between the gravel layer and the dust layer through an indoor experiment.

An experimental study on the waveforms of waves reflected from underground burials was conducted to evaluate the possibility of using GPR to analyze materials that can be used for ground cavity restoration schemes. ${ }^{(12)}$ In the study, the waveforms of each structure were classified, but for the actual ground, it was found that certain waveforms could not be read depending on the characteristics of the structure. In addition, in the case of a cavity, since there are many GPR signal overlapping lights, it was found that the removal of noise affects the performance of the GPR survey. ${ }^{(13)}$ The signal characteristics and co-sensing applicability of four GPR devices were compared and analyzed. A data processing method and joint signal analysis were also compared and analyzed. Through research, although there were some differences according to the equipment, GPR was applicable to joint exploration, and it was judged appropriate to use specialized software rather than general software. ${ }^{(13)}$ Research has also been conducted to explore underground caverns under a road. ${ }^{(14)}$ In another study, an analysis of the signal properties for GPR was carried out. Most of the above studies were exploration studies of underground facilities or caverns, and studies analyzing the accuracy of road density measurement or underground facility exploration have been insufficient. ${ }^{(15)}$

Recently, many potholes have been generated. Potholes are caused by heavy snow and torrential rain, as well as the material of the road, but the main cause is the rapid increase in damage associated with the insufficient investigation of the site. The biggest cause of the lack of compaction is that it takes a long time to measure the density at a site and reflect it in the construction, making corrective action impossible. ${ }^{(16)}$ In Korea, it takes about two days to evaluate the compaction of an asphalt pavement after its compaction, as shown in Fig. 1, making

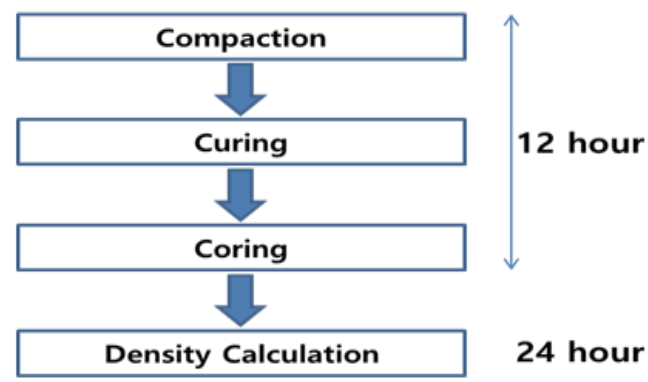

Fig. 1. (Color online) Conventional asphalt density calculation method. 
it impossible to provide immediate feedback at the site, and only the thickness of the laid asphalt layer is examined. ${ }^{(17)}$ Therefore, it is necessary to find a way to perform management by providing feedback in a short time in the field.

Therefore, in this study, the possibility of measuring the density of asphalt and concrete roads in the field using GPR was investigated. Also, the accuracy of underground facility exploration was analyzed to evaluate the additional utility of GPR. Figure 2 shows the flow of this study.

\section{Road Density Measurement}

\subsection{Data acquisition}

In this study, a pavement density profiler (PDP) was used to measure the road density. A PDP has the advantage of being able to rapidly determine the road density in the field. Ten roads (eight asphalt roads and two concrete roads) in Seoul were selected as study areas, and data were acquired using the PDP. Figure 3 shows the study area.

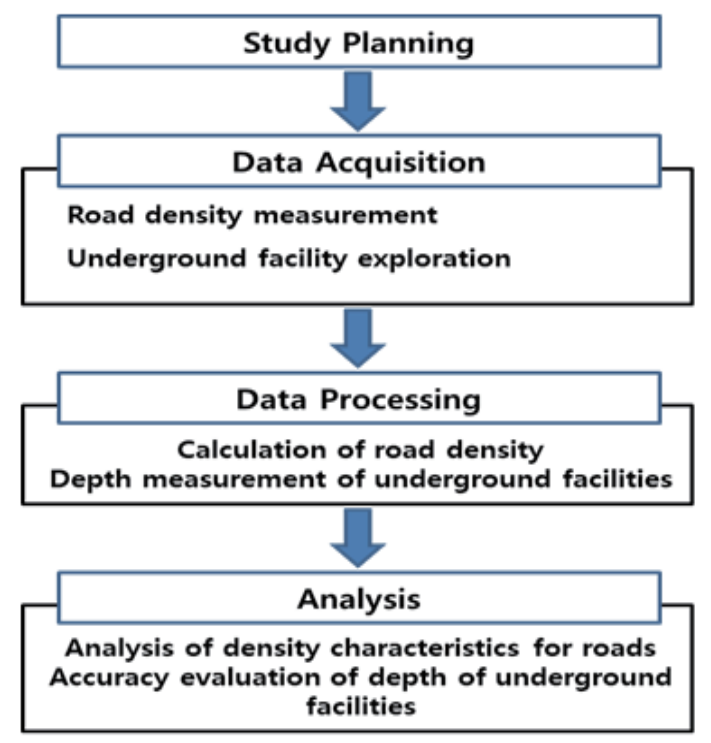

Fig. 2. (Color online) Study flow.

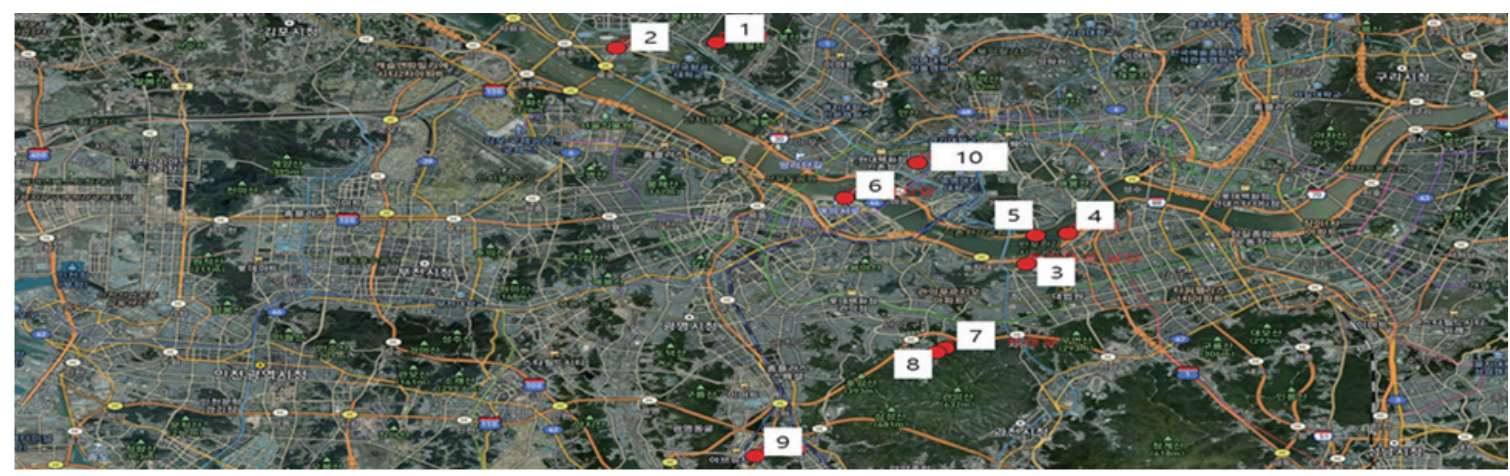

Fig. 3. (Color online) Study area for measurement of road density. 
Data were acquired continuously at the 10 sites using the PDP, whose locations were also acquired using the Global Navigation Satellite System (GNSS). Information about locations is very important for data processing and analysis and for the subsequent data management. The virtual reference station (VRS) method was used to obtain accurate location information, and the acquired locations were recorded. Table 1 lists the locations of the study areas.

Data acquisition took place over 5 to $30 \mathrm{~min}$. Data were acquired at $1 \mathrm{~s}$ intervals, and the bulk density and air void content were recorded. Table 2 lists the obtained values and Figs. 4 and 5 show road density and air void profiles obtained at two of the study areas.

\subsection{Analysis of road density}

At each of the 10 sites, one to six lines of data were acquired, and the acquired data were averaged for each line. Table 3 shows the bulk density and air void content for each line of each study area.

Table 1

Locations of study areas.

\begin{tabular}{rcccc}
\hline No. & Name & Latitude $(\mathrm{deg})$ & Longitude $(\mathrm{deg})$ & Road type \\
\hline 1 & Korea Aerospace University & 37.602860 & 126.865957 & asphalt \\
2 & Jayu-ro & 37.599538 & 126.830343 & asphalt \\
3 & Dongjak Bridge 1 & 37.505225 & 126.980147 & concrete \\
4 & Submerged Bridge & 37.519213 & 126.994535 & concrete \\
5 & Dongjak Bridge 2 & 37.518027 & 126.983195 & asphalt \\
6 & National Assembly & 37.533598 & 126.914265 & asphalt \\
7 & Seoul National University 1 & 37.466863 & 126.951767 & asphalt \\
8 & Seoul National University 2 & 37.465165 & 126.949027 & asphalt \\
9 & Gwangmyeong Station & 37.417315 & 126.885167 & asphalt \\
10 & Sogang University & 37.550160 & 126.939802 & asphalt \\
\hline
\end{tabular}

Table 2

Bulk density and air void content obtained by data acquisition.

\begin{tabular}{lcc}
\hline Trace number & Bulk density $\left(\mathrm{g} / \mathrm{cm}^{3}\right)$ & Air void content $(\%)$ \\
\hline 1 & 1.985044 & 16.59 \\
2 & 1.991403 & 16.33 \\
3 & 1.990754 & 16.35 \\
4 & 1.955855 & 17.82 \\
5 & 2.001145 & 15.92 \\
6 & 1.97973 & 16.82 \\
7 & 1.933187 & 18.77 \\
8 & 1.901849 & 20.09 \\
9 & 1.940338 & 18.47 \\
10 & 1.948963 & 18.11 \\
11 & 1.959842 & 17.65 \\
12 & 1.977779 & 16.9 \\
13 & 1.976869 & 16.94 \\
14 & 1.939825 & 18.49 \\
15 & 1.960515 & 17.63 \\
$\vdots$ & $\vdots$ & $\vdots$ \\
\hline
\end{tabular}




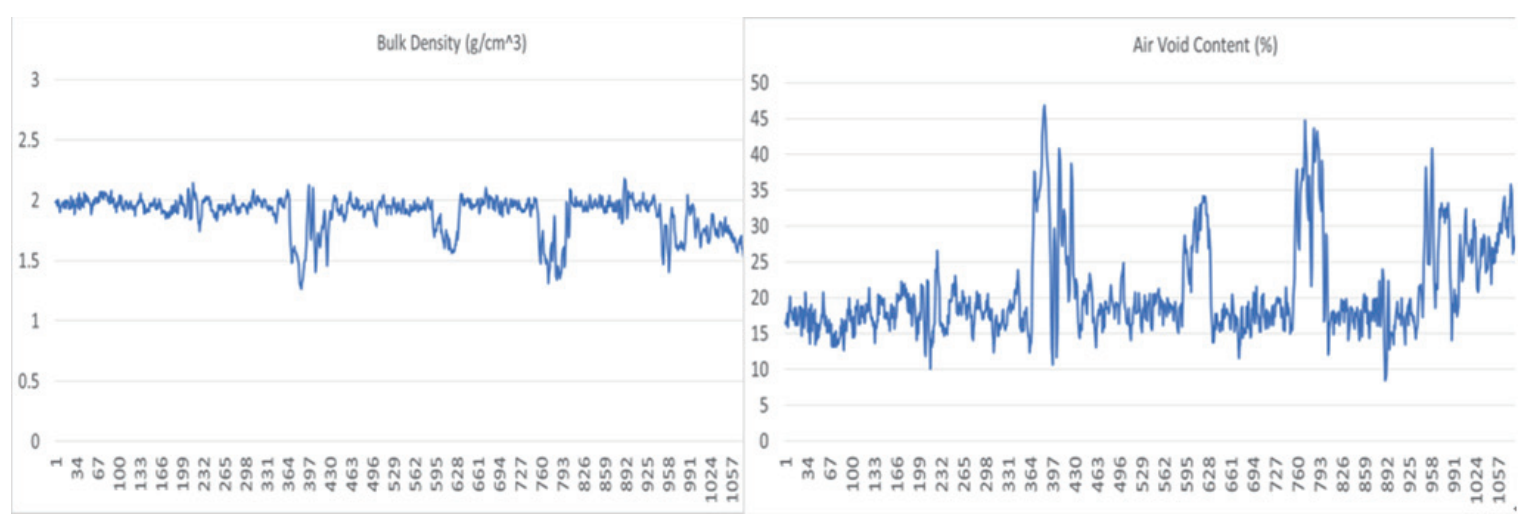

Fig. 4. (Color online) Road density and air void - Korea Aerospace University.

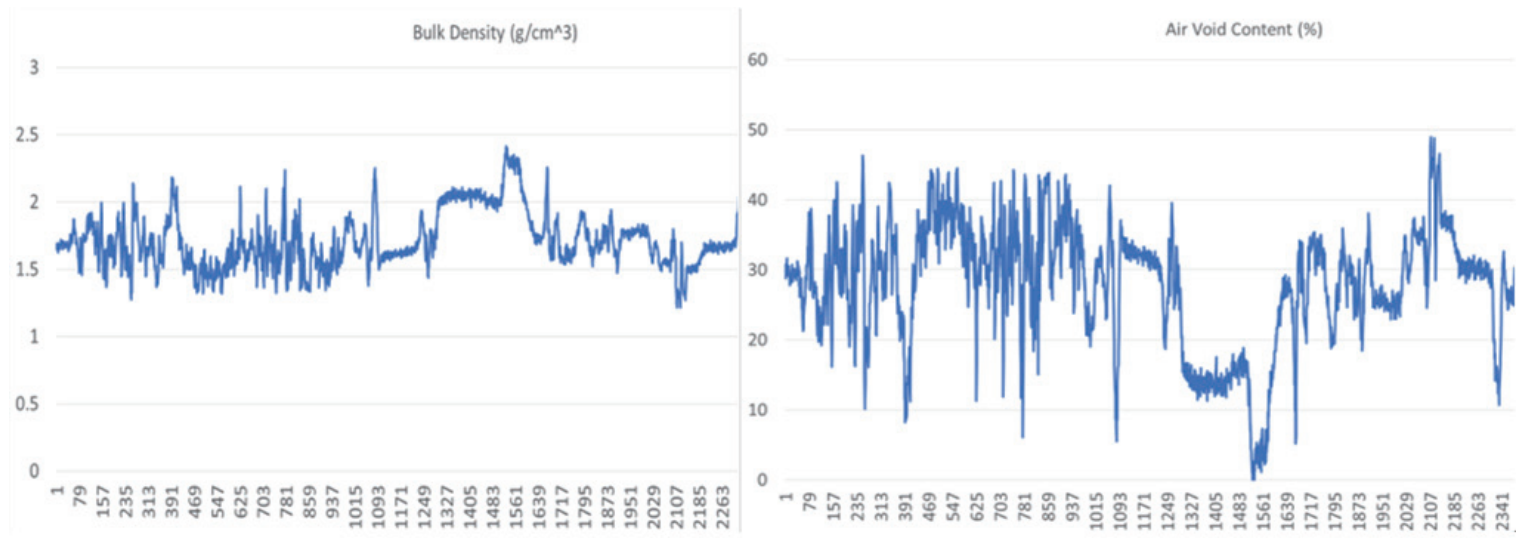

Fig. 5. (Color online) Road density and air void - Jayu-ro.

Density is one of the most important parameters in the construction of roads, and the local asphalt pavement density and air void content are among the various criteria used to assess the potential performance of asphalt pavement, making it highly advantageous to obtain their values directly on site. The values obtained at the research site were $2.1-2.5 \mathrm{~g} / \mathrm{m}^{3}$ for asphalt roads and $2.9-3.1 \mathrm{~g} / \mathrm{m}^{3}$ for concrete roads. Figure 6 shows the densities of asphalt and concrete roads.

The densities in Fig. 6 represent the average values of the data obtained from the study area. When calculating the densities, air void values close to 0 were excluded. To confirm the correctness of the densities, it was previously necessary to measure them in a laboratory and correlate them with those measured in the field. The density of asphalt calculated by the conventional method is $2.3-2.4 \mathrm{~g} / \mathrm{m}^{3}{ }^{(18)}$ which is similar to that obtained in this study. However, since a PDP can check these values in the field and the location can be recorded using the GNSS, it can be effectively used for road inspection. Further research is needed to analyze the accuracy of values measured by a PDP through future experiments. 
Table 3

Bulk density and air void content for each study area.

\begin{tabular}{|c|c|c|}
\hline Study area & Bulk density $\left(\mathrm{g} / \mathrm{cm}^{3}\right)$ & Air void content $(\%)$ \\
\hline \multirow{6}{*}{ Korea Aerospace University } & 2.3529 & 17.9440 \\
\hline & 2.3518 & 17.9923 \\
\hline & 2.3599 & 17.6492 \\
\hline & 2.3992 & 16.0015 \\
\hline & 2.3994 & 15.9900 \\
\hline & 2.3591 & 17.6857 \\
\hline \multirow{7}{*}{ Jayu-ro } & 2.7468 & 1.5253 \\
\hline & 2.7377 & 1.8627 \\
\hline & 2.1543 & 26.2900 \\
\hline & 2.1457 & 26.6534 \\
\hline & 2.1881 & 24.8703 \\
\hline & 2.0686 & 29.8891 \\
\hline & 2.0743 & 29.6509 \\
\hline \multirow{4}{*}{ Dongjak Bridge 1} & 3.1555 & 14.4757 \\
\hline & 3.1970 & 15.9457 \\
\hline & 2.9806 & 15.7413 \\
\hline & 2.9483 & 14.7467 \\
\hline \multirow{2}{*}{ Submerged Bridge } & 3.0144 & 0.0053 \\
\hline & 2.9860 & 0.0254 \\
\hline \multirow{3}{*}{ Dongjak Bridge 2} & 2.3058 & 19.9256 \\
\hline & 2.5351 & 10.3275 \\
\hline & 2.5331 & 10.3759 \\
\hline \multirow{2}{*}{ National Assembly } & 2.2581 & 21.9291 \\
\hline & 2.2459 & 22.4419 \\
\hline \multirow{4}{*}{ Seoul National University 1} & 2.1099 & 28.1569 \\
\hline & 2.1106 & 28.1266 \\
\hline & 1.8241 & 40.1641 \\
\hline & 1.7984 & 41.2441 \\
\hline \multirow{2}{*}{ Seoul National University 2} & 2.4632 & 13.3104 \\
\hline & 2.4752 & 12.8055 \\
\hline \multirow{2}{*}{ Gwangmyeong Station } & 2.2846 & 20.8140 \\
\hline & 2.2555 & 22.0389 \\
\hline Sogang University & 2.5673 & 8.9400 \\
\hline
\end{tabular}

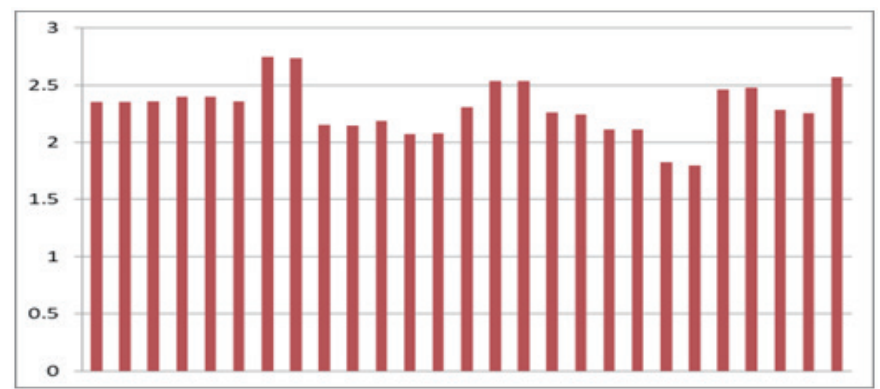

(a)

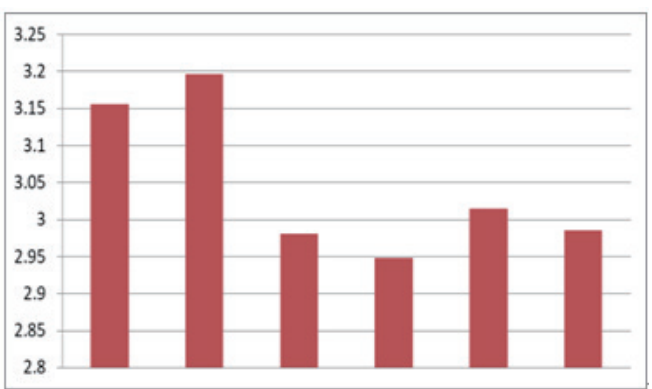

(b)

Fig. 6. (Color online) Densities of (a) asphalt and (b) concrete roads. 


\section{Underground Facility Measurement}

\subsection{Data acquisition}

An experiment was conducted to determine the possibility of exploring underground facilities using GPR. Part of Ilsan, Gyeonggi-do was selected as the study site, and its underground facilities were explored. Since the depth of the water supply pipeline in the study site is known through an underground facility survey, it is appropriate to evaluate the accuracy of underground facility exploration using GPR. Figure 7 shows the study area. Since the GPR equipment is equipped with a GNSS antenna, the location and depth of each underground facility can be identified together.

In Fig. 7, the red lines are the data acquisition paths, and the depth of the underground facility and the diameter of the water supply pipe were measured at the points indicated by circles. Data were acquired from a total of 30 points, and some of the results are shown in Fig. 8.

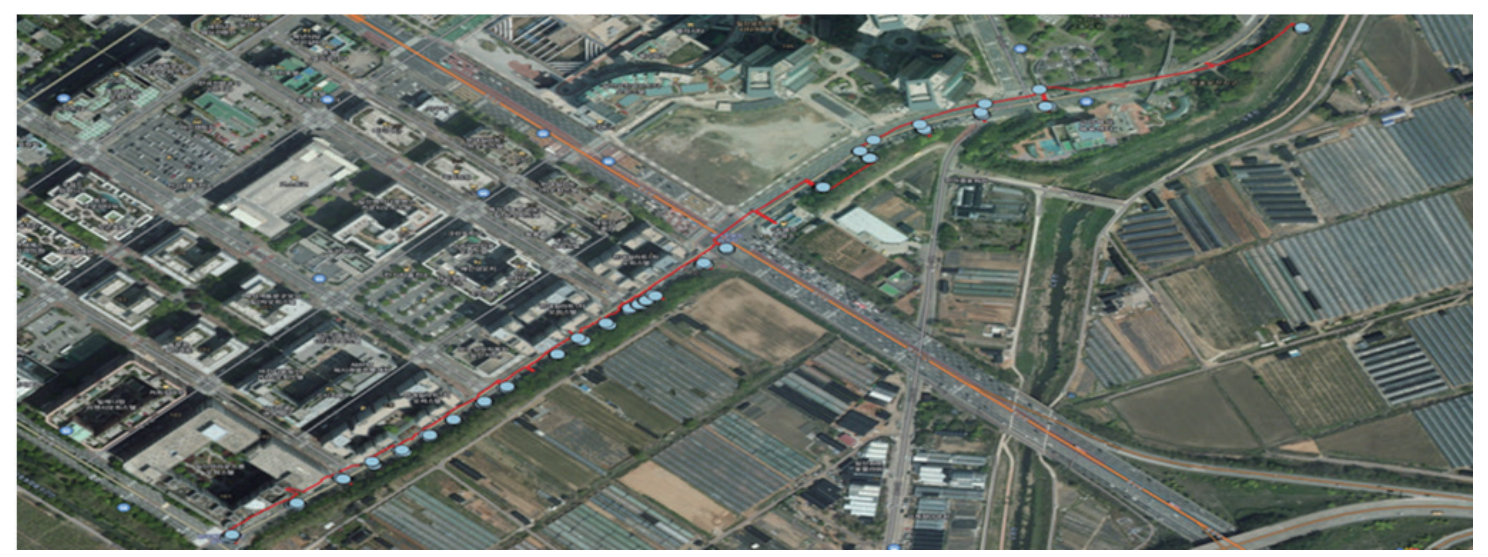

Fig. 7. (Color online) Study area for underground facility measurement.

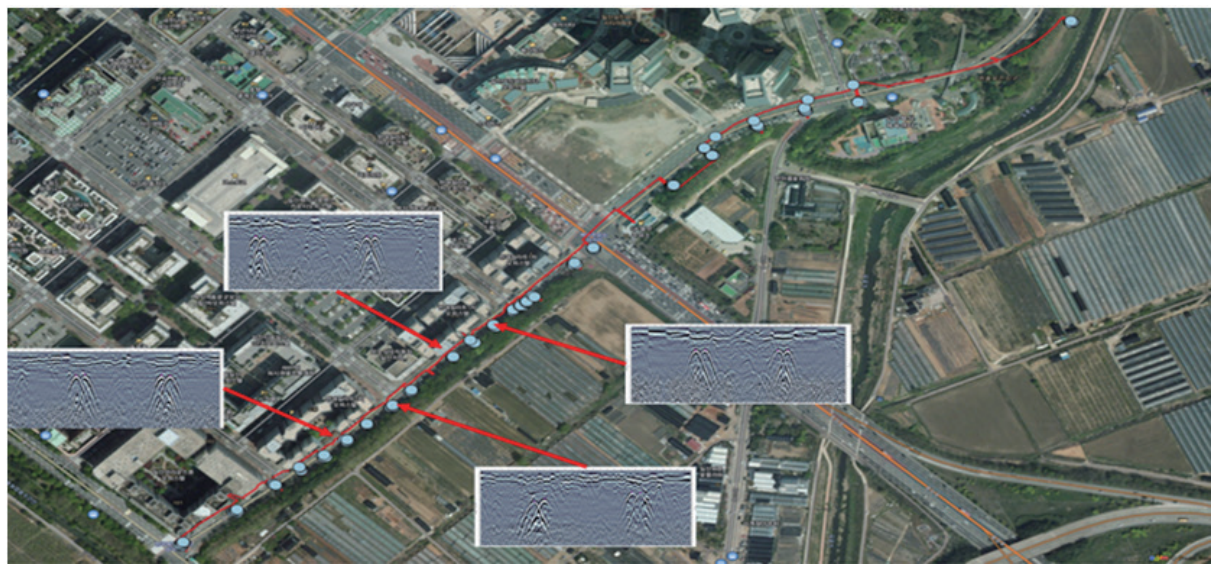

Fig. 8. (Color online) GPR measurement results. 


\subsection{Accuracy analysis}

Through the analysis of the GPR data acquired at each station, the depth and diameter of the water pipe were calculated at 30 points. Figure 9 shows how the depth and diameter of the water pipe were calculated. The accuracy was evaluated only for the depth of the water pipe. Table 4 shows the results of the accuracy evaluation.

The accuracy of the GPR depth was found to be $0.06-0.19 \mathrm{~m}$ as shown in Table 4 . In the case of GPR measurement, it is convenient to organize and use the data because it is possible to

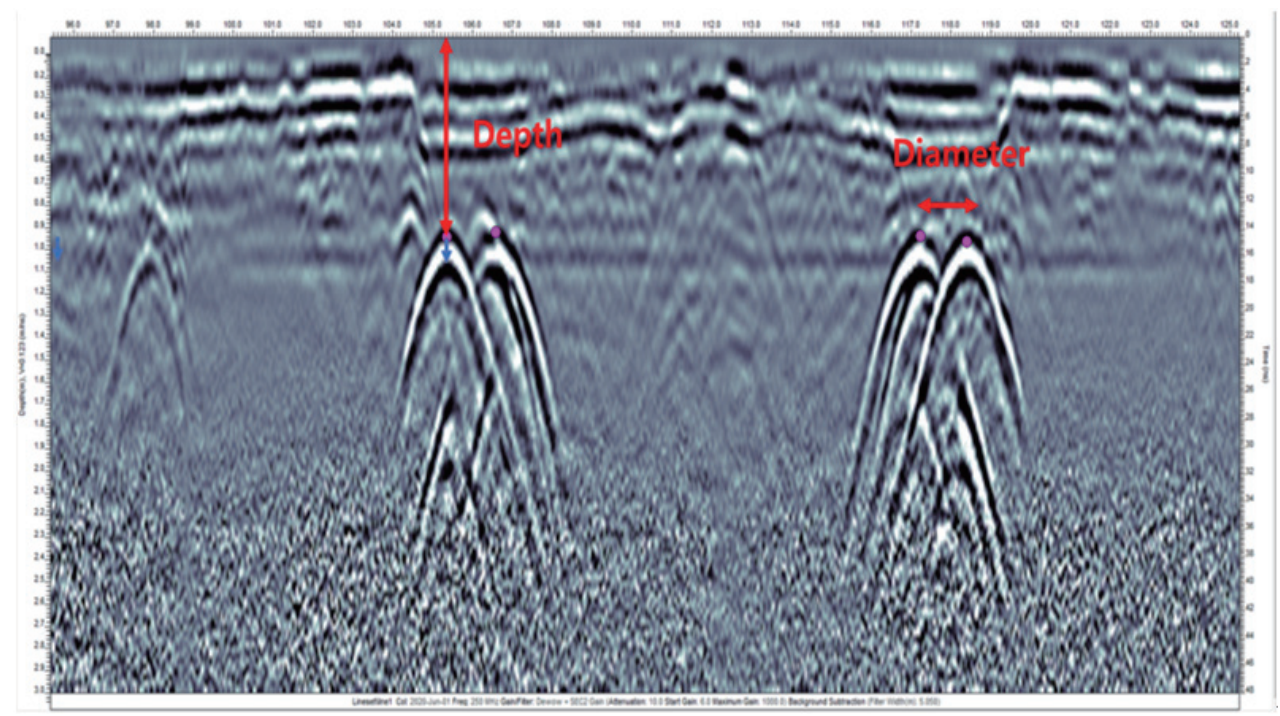

Fig. 9. (Color online) Calculation of depth and diameter of water pipe.

Table 4

Results of accuracy evaluation.

\begin{tabular}{|c|c|c|c|c|c|c|c|}
\hline No. & $\begin{array}{l}\text { Reference } \\
\text { depth (m) }\end{array}$ & GPR (m) & Deviation (m) & No. & $\begin{array}{l}\text { Reference } \\
\text { depth (m) }\end{array}$ & GPR (m) & Deviation (m) \\
\hline 1 & 1.14 & 1.04 & 0.10 & 16 & 1.04 & 0.98 & 0.06 \\
\hline 2 & 1.10 & 1.02 & 0.08 & 17 & 1.12 & 0.94 & 0.18 \\
\hline 3 & 1.11 & 0.98 & 0.13 & 18 & 1.07 & 0.92 & 0.15 \\
\hline 4 & 1.05 & 0.98 & 0.07 & 19 & 1.08 & 0.92 & 0.16 \\
\hline 5 & 1.07 & 0.97 & 0.10 & 20 & 1.04 & 0.92 & 0.12 \\
\hline 6 & 1.12 & 1.01 & 0.11 & 21 & 1.10 & 0.94 & 0.16 \\
\hline 7 & 1.13 & 1.02 & 0.11 & 22 & 1.11 & 0.94 & 0.17 \\
\hline 8 & 1.05 & 0.91 & 0.14 & 23 & 1.14 & 0.95 & 0.19 \\
\hline 9 & 1.04 & 0.92 & 0.12 & 24 & 1.15 & 0.98 & 0.17 \\
\hline 10 & 1.05 & 0.97 & 0.08 & 25 & 1.17 & 1.04 & 0.13 \\
\hline 11 & 1.18 & 1.05 & 0.13 & 26 & 1.19 & 1.05 & 0.14 \\
\hline 12 & 1.21 & 1.08 & 0.13 & 27 & 1.19 & 1.01 & 0.18 \\
\hline 13 & 1.21 & 1.06 & 0.15 & 28 & 1.18 & 1.04 & 0.14 \\
\hline 14 & 1.2 & 1.07 & 0.13 & 29 & 1.17 & 1.05 & 0.12 \\
\hline 15 & 1.19 & 1.1 & 0.09 & 30 & 1.19 & 1.07 & 0.12 \\
\hline
\end{tabular}


Table 5

Criteria for the accuracy of underground facilities survey equipment.

\begin{tabular}{lcc}
\hline Item & Depth range & Accuracy \\
\hline Allowable value & $3 \mathrm{~m}$ & $0.3 \mathrm{~m}$ \\
\hline
\end{tabular}

record the location where data are acquired using GNSS. The reference value is very accurate because it is calculated using the value measured when installing the water pipe. The accuracy of the pipe depth measured by GPR in this study is considered to be sufficient for surveying underground facilities. Table 5 shows the criteria for the accuracy of underground facilities survey equipment. ${ }^{(19)}$

Since the accuracy standard of a metal pipe detector used for surveying underground facilities is $0.3 \mathrm{~m}$, GPR can be used for pipe detection. If GPR is used for surveying underground facilities, it will be possible to significantly improve the efficiency of related work because the exact location and depth of the pipe can be recorded.

\section{Conclusions}

In this study, GPR was used to investigate the possibility of measuring the density of asphalt and concrete roads in the field. Additionally, the accuracy of underground facility exploration using GPR was analyzed. To measure the road density, 10 roads in Seoul were selected, and data from which were acquired. The road densities in the study sites obtained through PDP measurement ranged from 2.1 to $3.1 \mathrm{~g} / \mathrm{m}^{3}$ and depended on the road material. The local asphalt pavement density and air void content are among the various criteria used to evaluate the potential performance of asphalt pavement, making it highly advantageous to obtain their values directly on site. A PDP is very efficient because values in the field can be examined more simply than by the conventional method of calculation through an indoor experiment. However, additional comparative studies are needed to verify its applicability. In addition, in this study, we confirmed the possibility of exploring underground facilities using GPR. In our experiment, an area where the depth of actual water supply pipes was known was selected as the study site, and data acquisition and analysis were performed using GPR. The accuracy of the underground facility exploration using GPR was $0.06-0.19 \mathrm{~m}$. This means that it satisfies the criteria for surveying underground facilities. When using GPR for underground facility surveying, the exact location and depth of piping can be recorded, which can considerably increase the efficiency of related operations.

\section{Acknowledgments}

This research was supported by the Basic Science Research Program through the National Research Foundation of Korea (NRF) funded by the Ministry of Science and ICT (No. NRF2021R1F1A1061677). 


\section{References}

1 J. Y. Lee, J. W. Shim, S. R. Lee, and K. H. Lee: J. Korean Soc. Civil Eng. 40 (2020) 285. https://doi.org/10.12652/ Ksce.2020.40.3.0285

2 J. J. Park, E. C. Shin, K. S. Park, H. S. Shin, and G. W. Hong: J. Korea Soc. Disaster Inf. 14 (2018) 430. https:// doi.org/10.15683/kosdi.2018.12.31.430

3 C. M. Lee, J. S. Yoon, J. E. Baek, and S. T. Kim: J. Korean Soc. Road Eng. 21 (2020) 35. https://doi.org/10.7855/ IJHE. 2019.21.1.035

4 H. Y. Ko and N. G. Kim: J. Con. Inf. Tec. 9 (2019) 21. https://doi.org/10.22156/CS4SMB.2019.9.5.021

5 S. H. Lee and I. H. Jang: J. Korean Geo-Env. Soc. 20 (2019) 49. https://doi.org/10.14481/jkges.2019.20.2.49

6 H. H. Lee: J. Korea Ins. Str. Main. Ins. 20 (2016) 86. https://doi.org/10.11112/jksmi.2016.20.2.086

7 J. H. Choo, C. K. Yoo, Y. C. Oh, and I. M. Lee: J. Korean Tun. Under. Space Ass. 21 (2019) 717. https://doi. org/10.9711/KTAJ.2019.21.5.717

8 B. N. Kim, S. J. Seol, and J. M. Byun: Geophys. Geo. Exp. 20 (2017) 61. https://doi.org/10.7582/ GGE.2017.20.2.061

9 S. Y. Hyun: J. Korean Ins. Ele. Eng. Sci. 29 (2018) 61. https://doi.org/10.5515/KJKIEES.2018.29.1.61

10 D. Y. Lee: J. Korean Geo. Soc. 17 (2018) 47. https://doi.org/10.12814/jkgss.2018.17.3.047

11 B. J. Park, G. G. Kim, J. S. Lee, M. S. Kang, and Y. K. An: Remote Sens. 10 (2018) 1417. https://doi.org/10.3390/ rs10091417

12 K. S. Kim, J. S. Choi, and J. S. Yoon: Int. J. Highway Eng. 20 (2018) 117. https://doi.org/10.7855/ IJHE.2018.20.6.117

13 J. Y. Kim and C. H. Choi: J. Korean Geo-Env. Soc. 19 (2018) 13. https://doi.org/10.14481/jkges.2018.19.7.13

14 Y. S. Han and W. S. Kim: J. Korean Soc. Dis. Sec. 10 (2017) 47. https://doi.org/10.21729/ksds.2017.10.1.47

15 Y. T. Kim, J. Y. Choi, K. D. Kim, and H. M. Park: Int. J. High. Eng. 19 (2017) 69. https://doi.org/10.7855/ IJHE.2017.19.5.069

16 S. H. Kang, J. S. Lee, S. J. Lee, J. W. Lee, and W. T. Hong: J. Eng. Geo. 27 (2017) 217. https://doi.org/10.9720/ kseg.2017.3.217

17 J. H. Shin, Y. T. Choi, and S. Y. Jang: J. Korean Geo-Env. Soc. 18 (2017) 13. https://doi.org/10.14481/ jkges.2017.18.4.13

18 D. R. Son: J. Korean Magn. Soc. 30 (2020) 106. https://doi.org/10.4283/JKMS.2020.30.3.106

19 The National Law Information Center: http://www.law.go.kr/ (accessed August 2020). 